\title{
A Numerical and Experimental Study of the RCF Behaviour of PVD-coated Spur Gears
}

\author{
Sergio Baragetti ${ }^{1, a}$, Stefano Cavalleri ${ }^{1, b}$ and Federico Tordini ${ }^{1, c}$ \\ ${ }^{1}$ Department of Design and Technology, University of Bergamo, Viale Marconi 5, \\ 24044, Dalmine (BG), Italy \\ asergio.baragetti@unibg.it, ${ }^{b}$ stefano.cavalleri@unibg.it, cfederico.tordini@unibg.it
}

\section{Keywords: PVD coatings, Rolling contact fatigue, Crack growth rate, Spur gears, Numerical models}

\begin{abstract}
In this work the rolling contact fatigue (RCF) behaviour of WC/C PVD-coated and uncoated case hardened transmission gears for competition motorcycles was studied both numerically and experimentally. Finite element models of the gears were processed and a theoretical-numerical procedure was applied to the numerical results to predict their RCF life. The presence of the coating and the residual stress fields induced by the surface treatments were simulated. Besides $16 \mathrm{NiCr} 11$, which is the actual material of the gears analyzed, the Ti-6Al-4V alloy was also considered with the numerical models. Preliminary RCF tests were carried in both dry and lubricated condition to observe the damage on the tooth flanks with and without the presence of the coating.
\end{abstract}

\section{Introduction}

As a matter of fact, RCF is the main source of failure for transmission gears. The progressive damaging which develops from either surface or subsurface crack initiation sites and leads to pitting or spalling formation on the tooth flanks can be limited with traditional surface hardening treatments such as case hardening or nitriding. Thin hard coatings deposited by means of PVD (Physical Vapor Deposition) technique can represent another effective surface treatment from this point of view [1]. The presence of high surface residual compressive stresses due to the deposition process can prove effective against RCF [1,2]. PVD coatings such as WC/C are currently used to increase the wear resistance and to lower the friction losses of automotive transmission gears. Up to now, the tribological and mechanical characterization of $\mathrm{WC} / \mathrm{C}$ coatings has been mainly studied [3-5] rather than their influence on the RCF behaviour of the base material. Also, the rising need for lightening mechanical components is expected to make the use of light alloys be larger and larger in a number of applications. These materials often show high strength and corrosion resistance but less interesting fatigue behaviour, wear resistance and load bearing capacity with respect to the traditional steels. Therefore, the deposition of suitable coatings on light alloys to achieve performances similar to or even better than those of steels would be much important for structural applications. Thin hard coatings can be beneficial to the fatigue behaviour of both steel and light alloys [6-9]. Nevertheless, the study of the RCF behaviour of coated light alloys has not been developed enough yet. The prediction of the number of load cycles until subsurface damage initiation from RCF and of the crack growth until spall formation in coated and uncoated transmission gears has already been addressed by the authors [10-12]. As far as it is known, models to foresee the RCF crack growth in uncoated gears only can be found in the literature [13-18]. In this work a theoretical-numerical procedure was used to foresee the RCF behaviour of uncoated and WC/C PVD-coated spur gears of a Ducati 1098R competition motorcycle. Finite element models of the gears were developed to simulate the crack growth up to the external surface from a small subsurface defect placed in the tooth contact area where the initial damage was supposed to occur under RCF. On top of the actual material of the gears, i.e. case hardened $16 \mathrm{NiCr} 11$, Ti-6 Al- $4 \mathrm{~V}$ was also analyzed. Both the coating presence and the residual stress fields induced by the surface treatments were simulated and a torque higher than the maximum service one was applied. Preliminary RCF tests were carried out on the uncoated and the PVD-coated steel gears in both dry and lubricated condition to evaluate the damage on the tooth flanks by applying the same torque of the models for 30,000 load cycles.

\section{Numerical models}

Two-dimensional models of the meshing gears constituting the sixth speed of a Ducati 1098R were developed with the FE code ABAQUS. The main parameters of the gears are listed in Table 1. Two different base materials were analyzed, namely the actual $16 \mathrm{NiCr} 11$ steel alloy and the alpha-beta Ti-6Al-4V titanium alloy. The coating was a 3 $\mu \mathrm{m}$-thick PVD-deposited WC/C low friction film. The mechanical properties of the base materials and of the coating are reported in Table 2. Linear elastic FE models were developed by using 4-node bilinear plain strain quadrilateral elements (CPE4) for the bulk materials and 2-node linear 2-D truss elements (T2D2) for the coating. The hypothesis of absence of delamination between coating and substrate was also assumed. The applied torque 
was $300 \mathrm{Nm}$. A value $20 \%$ higher than the maximum service torque was assumed since the study of the performance of the coating and of the base materials under RCF with overloading condition was addressed.

Table 1 - Main parameters of the gears studied

\begin{tabular}{lcc}
\hline & Pinion & Driven gear \\
\hline Modulus [mm] & 2.5 & 2.5 \\
Tooth thickness [mm] & 13 & 13 \\
Tooth number & 25 & 22 \\
Pitch diameter [mm] & 64.9 & 57.1 \\
\hline
\end{tabular}

Table 2 - Mechanical properties of the base materials and coating.

\begin{tabular}{lccc}
\hline & 16NiCr11 & Ti-6Al-4V & WC/C \\
\hline Density [kg/m ${ }^{3}$ ] & 7800 & 4500 & $\sim 15000$ \\
Young's modulus [MPa] & 206000 & 113000 & 300000 \\
Poisson's ratio & 0.3 & 0.34 & 0.2 \\
YS [MPa] & 785 & 880 & $/$ \\
UTS [MPa] & $1030-1280$ & 950 & $/$ \\
\hline
\end{tabular}

The coupling-kinematic interaction was used to constrain both the gears to their own axis of rotation to allow the application of the torque and the imposition of the boundary conditions [11]. The whole contact arc was evaluated by imposing ten rotation steps of $0.85^{\circ}$ each to the meshing gears. The submodelling technique was used to refine the mesh to improve the accuracy of the results over the contact area on the tooth flanks. Pre-stresses (S11 in Fig.1) oriented along the tooth flank tangential direction were introduced into suitable solid partitions to reproduce the residual stresses induced by the surface treatments. The position and the orientation of the subsurface initial defect were assumed so as to comply with a possible initial damage due to RCF [9-14]. An initial defect length equal to 5 $\mu \mathrm{m}$ was assumed for both the steel and the titanium gears and, in order to prevent the crack mating flanks from overlapping, suitable contact gap elements were used. Fig. 1 shows a global model and its submodel with the visualization of the initial defect. The rear crack tip (Fig. 1) is the first involved in the meshing cycle. The numerical results allowed the calculation of the mixed mode stress intensity factor $\left.\Delta K=\sqrt{[}\left(K_{I}^{2}+K_{I I}^{2}\right)\left(1-v^{2}\right)\right]$ for both the rear and the fore crack tip over the complete meshing cycle according to [11]. The crack propagation was predicted by applying the microstructural fracture mechanics and a model developed for case hardened spur gears which requires the knowledge of the surface microhardness field to calculate the critical stress intensity factor $K_{c}$, the threshold stress intensity factor range $\Delta K_{t h}$ and the hardness parameter $H[7,8,11]$. According to the model the crack growth rate can be determined by means of the following equations $[7,8]$ :

$$
\begin{aligned}
& \frac{d a}{d N}=\frac{C}{\left(1-\rho^{n}\right)}\left(\Delta K^{n}-\Delta K_{t h}^{n}\right) \quad \Delta K_{t h} \leq \Delta K \leq K^{*} \\
& \frac{d a}{d N}=\frac{C}{\left(1-\rho^{n}\right)}\left(\frac{\Delta K^{n} K_{c}}{K_{c}^{n}-\Delta K^{n}}\right) \quad K^{*} \leq \Delta K \leq K_{c} \\
& \rho=\frac{\Delta K_{t h}}{K_{c}}, \quad \log (C)=-10+1.09 \cdot 10^{-2} H-1.40 \cdot 10^{-5} H^{2}, K^{*}=\sqrt{\Delta K_{t h} K_{c}}, \quad n=4.31-8.66 \cdot 10^{-3} H+1.17 \cdot 10^{-5} H^{2}
\end{aligned}
$$
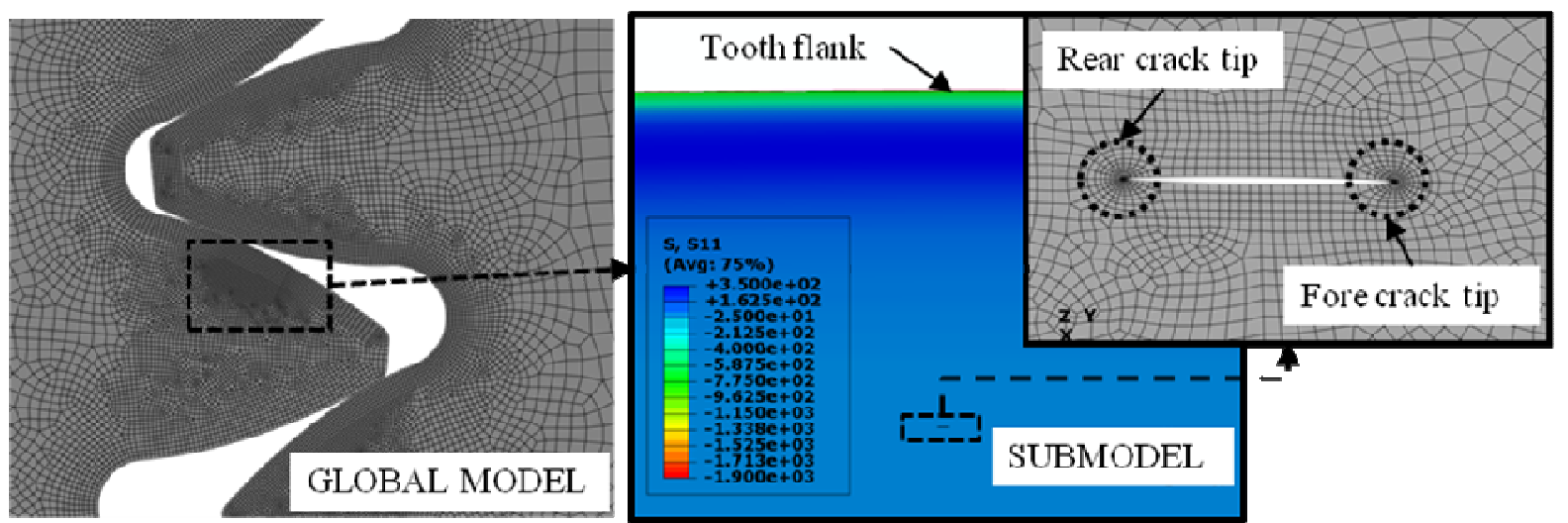

Figure 1 - FE model of the meshing gears with the visualization of the residual stresses due to the deposition process and of the initial crack in the submodel.

\section{Results and discussion}

The high value of torque applied made it possible for the $5 \mu \mathrm{m}$-long initial defect to grow under RCF regardless of the gear material and of the surface treatment. The maximum stress intensity factor range was higher than the threshold stress intensity factor range at both the rear and the fore crack tip. The propagation hence started from both the crack tips and initially followed a path coincident with the defect lying direction, i.e. only relative sliding between the crack mating faces occurred. The pure Mode II propagation characterized the first stages of the crack 
growth until the defect was at least $50 \mu \mathrm{m}$ long. Then the propagation direction deviated towards the external surface to form a spall under RCF. The maximum stress intensity factors at the crack tips were mainly found to occur during the last phase of the meshing cycle, i.e. when the tooth flank contact point was over the crack location. The rear crack front propagated with higher growth rates in all the gears along a linear path inclined of about $70^{\circ}$ with respect to the initial direction (Fig. 2). The propagation of both the defect sides was simulated until the rear propagating front emerged. Despite the mixed mode was pointed out after the initial stages of the crack growth, the Mode II contribution prevailed throughout the whole propagation process.
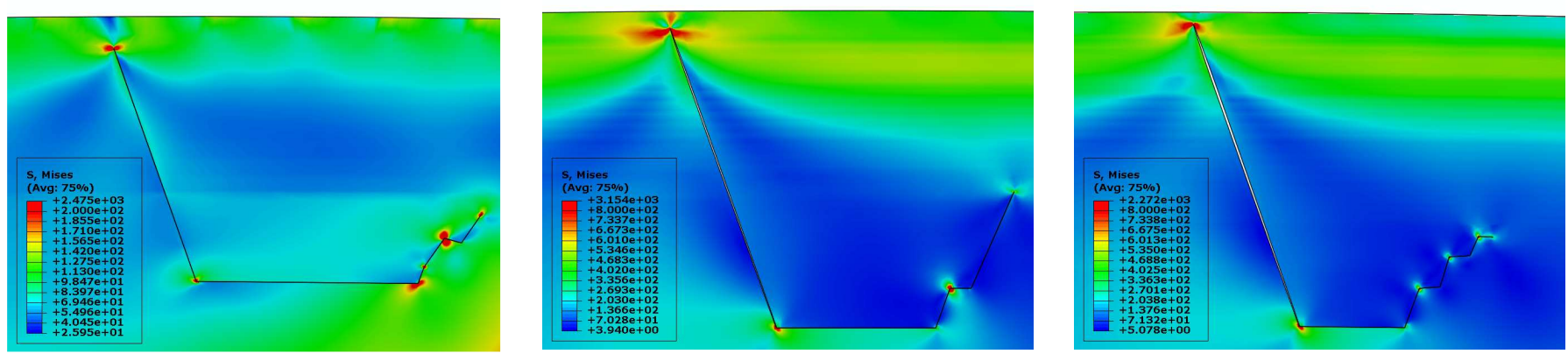

Figure 2 - Final stage of crack propagation under RCF in the case hardened (left), coated steel and coated titanium gear (right).

Table 3 reports the number of cycles needed to produce each crack length increment at the rear front calculated by applying the outlined procedure and the corresponding maximum stress intensity factor range and threshold stress intensity factor range. These parameter values are the mean ones over each crack length increment. By looking at the total numbers of cycles it is evident that the most effective treatment to prolong the RCF life of the gears is still the traditional case hardening. Nevertheless, it is important to highlight the improvement that can be achieved by using coated titanium instead of coated steel. The total number of cycles until the subsurface crack emerged under RCF was 6,710,000 for the coated titanium gear against 3,890,000 for the coated steel one - i.e. a $+72 \%$ increase was produced. Furthermore, it is also important to stress the fact that, as far as the coated steel gear is concerned, the majority of the fatigue life is spent during the first propagation phase $(5-50 \mu \mathrm{m})$. The remaining part is characterized by significantly higher crack growth rates, whereas lower numbers of cycles and stress intensity factors were calculated for the titanium gear throughout the whole crack propagation process. Also, in case of larger initial defects - i.e. at least $50 \mu \mathrm{m}$-long - the titanium base material would be able to retard their growth more effectively. In fact, by neglecting the initial crack increment the RCF life of the coated titanium gear is $3,670,000$ cycles against 814,000 for the coated steel one, which means a $+351 \%$ percentage increase. As a matter of fact, the lower crack growth rates found for the coated titanium gear significantly depends on the lower elastic modulus of the base material which results in lower stress intensity factor values [8]. The benefits from using coated titanium instead of steel are then supported by these results. Notwithstanding the higher fatigue life pointed out for the case hardened steel gear due to the higher penetration depth of the treatment effects, the use of suitably coated titanium gears would allow to have improved RCF properties and, at the same time, good tribological performances due to the coating presence. The relatively low penetration depth of the residual compressive stresses and of the surface hardened layer produced by the deposition process constitutes a key parameter to investigate. In fact, the presence of deeper compressive stresses could help significantly in retarding the propagation, as the numerical results for the case hardened gear show. This issue should also be addressed by the current deposition technique.

Table 3. Crack growth at the rear propagation front: number of cycles for each length increment until the crack emerges.

\begin{tabular}{|c|c|c|c|c|c|c|c|c|c|c|c|}
\hline \multicolumn{4}{|c|}{ Case hardened gear } & \multicolumn{4}{|c|}{ Coated steel gear } & \multicolumn{4}{|c|}{ Coated titanium gear } \\
\hline$\Delta a_{\text {rear }}$ & $\Delta N$ & $\Delta K$ & $\Delta K_{t h}$ & $\Delta a_{\text {rear }}$ & $\Delta N$ & $\Delta K$ & $\Delta K_{t h}$ & $\Delta a_{\text {rear }}$ & $\Delta N$ & $\Delta K$ & $\Delta K_{t h}$ \\
\hline$[\mu \mathrm{m}]$ & - & \multicolumn{2}{|c|}{$[\mathrm{MPa} \sqrt{\mathrm{m}}]$} & {$[\mu \mathrm{m}]$} & - & \multicolumn{2}{|c|}{$[\mathrm{MPa} \sqrt{\mathrm{m}}]$} & {$[\mu \mathrm{m}]$} & - & \multicolumn{2}{|c|}{$[\mathrm{MPa} \sqrt{ } \mathrm{m}]$} \\
\hline $5-50$ & $2.44 \mathrm{E}+06$ & 1.50 & 0.91 & $5-50$ & $3.08 \mathrm{E}+06$ & 1.46 & 1.13 & $5-50$ & $3.04 \mathrm{E}+06$ & 1.26 & 0.88 \\
\hline $50-75$ & $2.28 \mathrm{E}+06$ & 2.62 & 1.64 & $50-75$ & $2.45 \mathrm{E}+05$ & 2.79 & 2.02 & $50-70$ & $4.79 E+05$ & 1.86 & 1.30 \\
\hline $75-105$ & $3.17 \mathrm{E}+07$ & 1.54 & 1.08 & $75-95$ & $1.78 \mathrm{E}+05$ & 2.70 & 1.75 & $70-90$ & $1.78 \mathrm{E}+06$ & 1.12 & 0.75 \\
\hline $105-130$ & $6.67 \mathrm{E}+06$ & 2.01 & 1.07 & $95-125$ & $1.85 \mathrm{E}+05$ & 2.88 & 1.46 & $90-112$ & $6.36 \mathrm{E}+05$ & 1.57 & 0.85 \\
\hline $130-160$ & $1.10 \mathrm{E}+06$ & 3.13 & 1.55 & $125-150$ & $6.83 \mathrm{E}+04$ & 3.84 & 1.85 & $112-138$ & $1.50 \mathrm{E}+05$ & 2.82 & 1.48 \\
\hline $160-196$ & $2.61 \mathrm{E}+06$ & 2.67 & 1.21 & $150-190$ & $6.65 \mathrm{E}+04$ & 4.58 & 2.16 & $138-170$ & $1.58 \mathrm{E}+05$ & 2.97 & 1.51 \\
\hline $196-228$ & $2.60 \mathrm{E}+06$ & 2.62 & 1.45 & $190-225$ & $7.12 \mathrm{E}+04$ & 4.22 & 1.86 & $170-203$ & $4.69 \mathrm{E}+05$ & 2.34 & 1.73 \\
\hline \multirow[t]{2}{*}{$228-270$} & $3.65 \mathrm{E}+07$ & 1.64 & 1.27 & & & & & & & & \\
\hline & $8.59 \mathrm{E}+07$ & & & & $3.89 \mathrm{E}+06$ & & & & $6.71 \mathrm{E}+06$ & & \\
\hline
\end{tabular}


Fig. 3 shows a collection of optical microscope images of tooth flanks of the RCF-tested uncoated and WC/Ccoated steel spur gears. As a matter of fact, the high applied torque produced RCF damage in both dry and lubricated condition. Nevertheless, the presence of the lubricant was fundamental to limit the detrimental effect of the over-torque on the surface integrity. The capability of $\mathrm{WC} / \mathrm{C}$ to reduce wear and friction losses during the tooth engagement - even in dry condition - will be characterized with further tests at lower loads and higher numbers of cycles. These tests will also allow to address the experimental study of the RCF damage in high performance PVDcoated gears and to validate and refine the proposed procedure to predict the RCF life of these components. In particular, the influence of the elastic-plastic material behaviour on the RCF crack propagation will be investigated and included in a new theoretical-numerical previsional model.

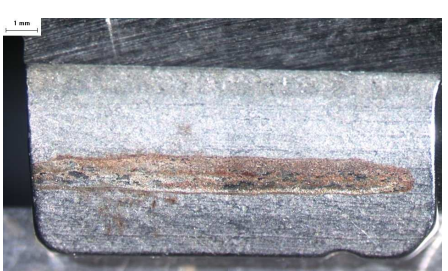

Case hardened, dry

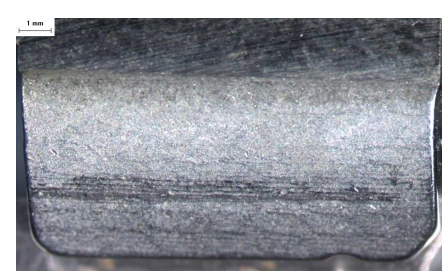

Case hardened, lubricated

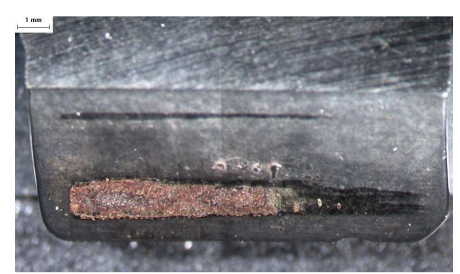

PVD-coated, dry

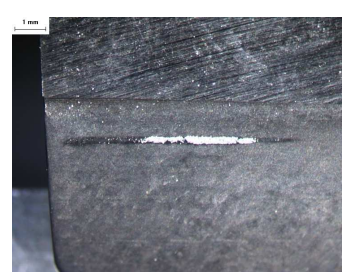

PVD-coated, lubricated

Figure 3 - Appearance of the RCF-tested tooth flanks after 30,000 load cycles; applied torque $=300 \mathrm{Nm}$.

\section{Summary}

A theoretical-numerical procedure to foresee the propagation of a subsurface small defect due to RCF damage in uncoated and PVD-coated transmission gears was developed. By applying a torque about $20 \%$ higher than the maximum service one, a $5 \mu \mathrm{m}$-long defect was found to propagate under RCF in all the gears studied. The lowest growth rate was determined for the (uncoated) case hardened gear. The coated titanium gear showed better RCF behaviour than the coated steel one. This could be mainly due the lower elastic modulus of the titanium alloy which results in lower stress intensity factor ranges at the crack tips. Therefore, the use of titanium as base material for PVD-coated spur gears could conveniently be taken into account as long as the effect of a deeper penetration of the deposition treatment effects on the RCF life is investigated with more and more numerical and experimental studies. Preliminary experimental RCF tests on the uncoated and the WC/C PVD-coated steel gears emphasized that with an over-torque applied even at relatively low numbers of cycles the presence of a lubricant is fundamental to protect the tooth flanks from being damaged regardless of the presence of the coating.

\section{Acknowledgments}

The Authors wish to thank DUCATI CORSE srl for the drawings and the data on the spur gears.

\section{References}

[1] S. Stewart, R. Ahmed: Wear Vol. 235 (2002), pp. 1132-1144.

[2] ASM Metals Handbook, edited by ASM International, 10th ed., Materials Park, OH (1993).

[3] P. Harlin, P. Carlsson, U. Bexell, M. Olsson: Surf Coat Technol Vol. 201 (2006), pp. 4253-4259.

[4] B. Navinšek, P. Panjan, M. Čekada, D.T. Quinto: Surf Coat Technol Vol. 154 (2002), pp. 194-203.

[5] K. Persson, R. Gåhlin: Tribol Int Vol. 36 (2003), pp. 851-855.

[6] K.R. Kim, C.M. Suh, R.I. Murakami, C.W. Chung: Surf Coat Technol Vol. 171 (2003), pp. 15-23.

[7] S. Baragetti, G.M. La Vecchia, A. Terranova: Int J Fat Vol. 27(10-12) (2005), pp. 1541-1550.

[8] S. Baragetti: Int J Fat Vol. 29 (2007), pp. 1893-1903.

[9] E.S. Puchi-Cabrera, M.H. Staia, J. Lesage, L. Gil, C. Villalobos-Gutiérrez, J. La Barbera-Sosa, E.A. OchoaPérez, E. Le Bourhis: Int J Fat Vol. 30 (2008), pp. 1220-1230.

[10] S. Baragetti, F. Tordini: Engineering with Computers, DOI: 10.1007/s00366-009-0167-9 (in course of publication).

[11] S. Baragetti, S. Cavalleri, F. Tordini: Key Engineering Materials Vols. 417-418 (2010), pp. 797-800.

[12] S. Baragetti, A. Terranova, F. Tordini: Key Engineering Materials Vols. 385-387 (2008), pp. 57-60.

[13] Y. Ding, J.A. Gear: Wear Vol. 267 (2009), pp. 1181-1190.

[14] M. Šraml, J. Flašker: Int J Adv Manuf Technol Vol. 31 (2007), pp. 1066-1075.

[15] G. Fajdiga, S. Glodež, J. Kramar: Wear Vol. 262 (2007), pp. 1217-1224.

[16] S. Glodež, B. Aberšek, J. Flašker, Z. Ren: Engng Fract Mech Vol. 71 (2004), pp. 429-438.

[17] K. Aslantaş, S. Taşgetiren: Wear Vol. 257 (2004), pp. 1167-1175.

[18] G. Fajdiga, Z. Ren, J. Kramar: Engng Fract Mech Vol. 74 (2007), pp. 2721-2734. 
Advances in Fracture and Damage Mechanics IX

10.4028/www.scientific.net/KEM.452-453

A Numerical and Experimental Study of the RCF Behaviour of PVD-Coated Spur Gears

10.4028/www.scientific.net/KEM.452-453.589 